SANDIA REPORT

SAND98-0451 • UC-905

Unlimited Release

Printed February 1998

RECEIVED

MAR 121998

OSTI

\title{
A One-Dimensional Analysis of Sol-Gel Film-Coating Drying: Pore Evolution, Network Shrinkage and Stress \\ Development
}

Ken S. Chen, P. Randall Schunk

Prepared by

Sandia National Laboratories

Albuquerque, New Mexico 87185 and Livermore, California 94550

Sandia is a multiprogram laboratory operated by Sandia Corporation,

a Lockheed Martin Company, for the United States Department of

Energy under Contract DE-AC04-94AL85000.

Approved for public release; further dissemination unlimited.

Ii Sandia National Laboratories
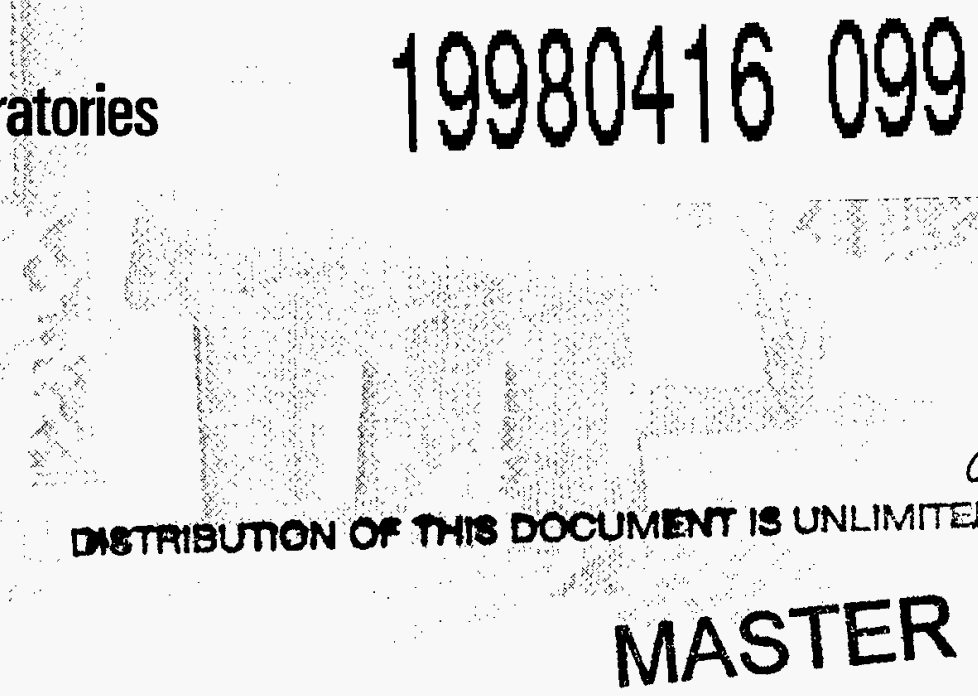

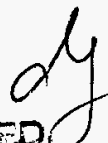

MASTER 
Issued by Sandia National Laboratories, operated for the United States Department of Energy by Sandia Corporation.

NOTICE: This report was prepared as an account of work sponsored by an agency of the United States Government. Neither the United States Government nor any agency thereof, nor any of their employees, nor any of their contractors, subcontractors, or their employees, makes any warranty, express or implied, or assumes any legal liability or responsibility for the accuracy, completeness, or usefulness of any information, apparatus, product, or process disclosed, or represents that its use would not infringe privately owned rights. Reference herein to any specific commercial product, process, or service by trade name, trademark, manufacturer, or otherwise, does not necessarily constitute or imply its endorsement, recommendation, or favoring by the United States Government, any agency thereof, or any of their contractors or subcontractors. The views and opinions expressed herein do not necessarily state or reflect those of the United States Government, any agency thereof, or any of their contractors.

Printed in the United States of America. This report has been reproduced directly from the best available copy.

Available to DOE and DOE contractors from

Office of Scientific and Technical Information

P.O. Box 62

Oak Ridge, TN 37831

Prices available from (615) 576-8401, FTS 626-8401

Available to the public from

National Technical Information Service

U.S. Department of Commerce

5285 Port Royal Rd

Springfield, VA 22161

NTIS price codes

Printed copy: A03

Microfiche copy: A01

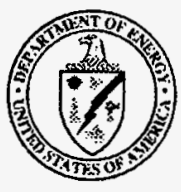




\section{DISCLAIMER}

This report was prepared as an account of work sponsored by an agency of the United States Government. Neither the United States Government nor any agency thereof, nor any of their employees, makes any warranty, express or implied, or assumes any legal liability or responsibility for the accuracy, completeness, or usefulness of any information, apparatus, product, or process disclosed, or represents that its use would not infringe privately owned rights. Reference herein to any specific commercial product, process, or service by trade name, trademark, manufacturer, or otherwise does not necessarily constitute or imply its endorsement, recommendation, or favoring by the United States Government or any agency thereof. The views and opinions of authors expressed herein do not necessarily state or reflect those of the United States Government or any agency thereof. 
SAND98-0451

Distribution

Unlimited Release

Category UC-905

Printed February 1998

\title{
A One-Dimensional Analysis of Sol-Gel Film-Coating Drying: Pore Evolution, Network Shrinkage and Stress Development
}

\author{
Ken S. Chen and P. Randall Schunk \\ Engineering Sciences Center \\ Sandia National Laboratories \\ P. O. Box 5800 \\ Albuquerque, New Mexico 87185 - 0826
}

\begin{abstract}
Highly porous sol-gel films have potential applications as electrical and thermal insulators, catalyst supports, sensors, and membranes for gas separations. Pore dimensions in these sol-gel films are usually small - e.g., on the order of tens of nanometers or less. Their successful fabrications, however, greatly depend on our fundamental understanding of mechanisms that underlie the phenomena of pore evolution, network shrinkage, and stress development since the final microstructure of a solid gel film is strongly affected by composition of its starting sol and its processing conditions. This report documents a simplified one-dimensional analysis of drying a solidifying sol-gel thin-film coating supported by an impermeable solid substrate. Portions of this work were presented at the 1994 Annual Joint Meeting of the New Mexico Section of the American Ceramic Society and Materials Research Society in Albuquerque. We considered the solid/liquid two-phase coexistent regime during the drying/solidifying process in which solvent is removed continuously via evaporation, the solid phase grows significantly in mechanical strength, and pore space shrinks appreciably. From overall and differential mass balances and a force balance at equilibrium, coupled with empirical correlations of solid-phase modulus and permeability to strain or deformation, we followed the evolution of pore space, solid-phase elastic stress, and liquid-phase hydrodynamic pressure; we also determined their respective values at equilibrium. By assuming microscopic pore-shape models, we estimated and compared the predicted mean pore radii. Our simplified one-dimensional analysis shows that the final mean pore radius is controlled by four parameters: pore-liquid surface tension, solid-phase modulus, mean pore radius, and porosity at the initial stress-free state. Our one-dimensional model can be employed to guide process design and optimization in sol-gel film fabrications.
\end{abstract}




\section{Acknowledgment}

We would like to thank A. J. Hurd for programmatic and funding support and C. J. Brinker for technical discussions. Technical exchanges/discussions with S. S. Prakash and G. W. Scherer during the course of this work were helpful. We are also indebted to Siu-yue Tam and R. A. Cairncross for proofreading of this manuscript. 


\section{CONTENTS}

1 INTRODUCTION 1

2 THEORETICAL MODEL AND ITS SOLUTION METHOD 2

3 RESULTS AND DISCUSSION 10

4 CONCLUSIONS 13

5 REFERENCES 13 


\section{INTRODUCTION}

The sol-to-gel process has been demonstrated to be a convenient technique for fabricating such products as electrical and thermal insulators, catalyst supports, sensors, and membranes for advanced gas separations (see, for example, Brinker and Scherer 1990; Brinker et al. 1996; Prakash et al. 1995; and Prakash 1995). Sol-gel films employed in these applications are highly porous, and pores are usually small - e.g., on the order of tens of nanometers or less. For a solgel film to be effective in applications as mentioned above, its mean pore size and pore-size distribution must be properly controlled; this is possible only if we have fundamental understanding of mechanisms that underlie the phenomena of pore evolution, network shrinkage, and stress development since the final microstructure of a solid gel film is strongly affected by composition of its starting sol and its processing conditions. This report documents a simplified one-dimensional analysis of drying a solidifying sol-gel thin-film coating supported by an impermeable solid substrate. Portions of this work were presented at the 1994 Annual Joint Meeting of the New Mexico Section of the American Ceramic Society and Materials Research Society in Albuquerque.

A sol-to-gel process typically starts by aging the inorganic polymer sol (consisting of - e.g., water, ethanol, tetraethoxysilane, and hydrochloric acid/ammonium hydroxide). The aged sol is then deposited onto a substrate support by dip coating (see, for example, Brinker and Scherer 1990, Chapter 13; see also Scriven 1988 and Schunk et al. 1996 for detailed discussion on film formation by dip coating). Once the aged sol film is coated onto the substrate support, the dynamic process of drying, solidification, and microstructure development can be conveniently divided into three regimes (gelation, pore evolution, and pore emptying) as schematically sketched in Figure 1. In the present study we consider only those sol-gel films with final pore dimensions much greater than the solvent-molecule size (e.g., more than a few nanometers) such that vapor/liquid interfaces are well defined and can be conveniently represented by menisci; in other words, we are not concerned with the solvation forces (which arise from the confined motion of solvent molecules in the pores) in the present study.

In the gelation regime the key phenomena are: solvent evaporation, solvent diffusion, hydrolysis/ condensation reactions, gelation evolved from localized clusters to form a sample-spanning gel network, and rapid rise in gel modulus. Here the drying surface remains flat - i.e., no curved menisci are formed. The onset of the pore-evolution regime is indicated by the appearance of menisci at the drying surface. This is a post-gelation (i.e., all hydrolysis/condensation chemical reactions have been completed), solid-liquid, two-phase coexistence regime. Here in this regime pores are formed within the gel film. Solvent transport is driven by pressure gradients - i.e., via Darcy flow. Capillary pressure forces develop within the pores and cause them to shrink. Simultaneously elastic stress develops in the solid gel network due to deformation. As the gel modulus rises, the resistance to deformation increases, and eventually the gel shrinkage stops when capillary forces are balanced by the resistance to deformation. In the pore-emptying regime menisci invade into pores while the solid network remains intact - i.e., no shrinkage occurs as pores are being emptied. When solvent is completely emptied out of the pores, capillary forces vanish due to the disappearances of menisci, and the "springback" phenomena, in which the shrunk pores expand back, can occur for certain types of gels (e.g., aerogels). The treatment of the "springback" phenomena is outside of the scope of the present study. 
In the area of drying and shrinkage of gels, Scherer (see, e.g. Scherer 1988, 1989, 1990, 1992; Scherer et al. 1995; Smith et al. 1995; Scherer and Smith 1995) has pioneered the theoretical development as well as empirical correlations for relevant physical properties (e.g., modulus and permeability). His extensive contributions to the research literature in this area have undoubtedly helped deepen our understanding of the complex phenomena of gel drying and shrinkage. Most recently a more generalized and multidimensional theoretical model was put forth by Cairncross et al. (1996) for drying deformable partially saturated porous media, such as sol-gel coatings, which removes some of the restrictions in Scherer's work (such as being restricted to cases in which analytical solutions to the governing equations could be obtained and to cases in which the pores remained filled with solvent). Cairncross et al.'s model takes into account of pore-size distribution and introduces the concept of saturation that enables modeling of the "springback" phenomena.

In the present study we focused on modeling phenomena in the pore evolution regime, and we aimed at developing a generalized one-dimensional platform on which relevant predictions (e.g. film thickness, mean pore size, stress in the gel network) can be computed to provide guidelines for process design and optimization in sol-gel film fabrication.

\section{THEORETICAL MODEL DEVELOPMENT}

\section{Governing Equations}

A schematic diagram of the sol-gel film drying process is shown in Figure 2. As was mentioned earlier the present model focuses on the pore evolution regime in which gelation is completed, and the liquid and solid phases co-exist. In particular we consider a thin gel film-coating with a thickness much less than its length and width so that edge effects can be safely neglected - i.e., variation is allowed only in the thickness direction. For simplicity, the solid substrate on which the gel film is supported is taken to be impermeable so that solvent evaporation occurs only at the top liquid/vapor interface. To further simplify our analysis, we introduce two additional assumptions: 1) the rate of pore-space reduction matches volumetric rate of solvent evaporation; in other words, the pore space is always filled completely with liquid and 2) the surface porosity is the same as the bulk porosity.

With the introduction of the above assumptions, the equations that govern the phenomena of drying, pore-evolution, and stress development can be derived easily from first principles. The pore space or liquid volume, $\mathrm{V}_{\mathrm{L}}$, is given by the overall mass balance of pore liquid:

$$
-\frac{d V}{d t} L=\phi A_{e} \dot{V}_{e}
$$

where $t$ is time, $\phi$ is porosity (recall the assumption of surface porosity being equal to the bulk porosity), $\mathrm{A}_{\mathrm{e}}$ is the area of solvent evaporation, and $\dot{v}_{e}$ is the volumetric rate of solvent evapora- 
tion per unit area that can be taken as constant or can be more realistically related to the vapor pressure using a mass transfer coefficient as follows:

$$
\dot{V}_{e}=k_{g}\left(p_{v}-p_{\nu \infty}\right)
$$

where $p_{v}$ is the vapor pressure just outside of the curved vapor/liquid interface, $p_{v \infty}$ the vapor pressure in the bulk of the overlying vapor, and $\mathrm{k}_{\mathrm{g}}$ the gas-phase mass transfer coefficient. Utilizing the Gibbs-Thompson (or Kelvin) equation, which relates the vapor pressure of the solvent liquid to the capillary pressure, we arrive at

$$
\dot{V}_{e}=k_{g} p_{\nu 0}\left(e^{-\frac{V_{m} p_{c}}{R T}}+\frac{p_{\nu \infty}}{p_{\nu 0}}\right)
$$

where $p_{\nu 0}$ is the vapor pressure just outside of a flat vapor/liquid interface, $\mathrm{V}_{\mathrm{m}}$ is the molar volume of the solvent, $R$ is the ideal-gas constant ( $\equiv 82.06 \mathrm{~cm}^{3} \mathrm{~atm} / \mathrm{gmol} \mathrm{K}$ ), $\mathrm{T}$ is temperature; and $\mathrm{p}_{\mathrm{c}}$ is the capillary pressure given by the Young-Laplace equation:

$$
p_{c}=\frac{2 \Upsilon \cos \theta_{c}}{r}
$$

Here $\gamma$ is pore-liquid or solvent surface tension, $\theta_{c}$ the contact angle of the liquid phase made with the solid gel wall, $r$ the radius of curvature of the vapor/liquid interface.

The pore-liquid pressure distribution is given by the continuity equation of the pore liquid that states that the volumetric Darcy flux of the pore liquid is balanced exactly by the rate of change in pore volume:

$$
\frac{1}{V} \frac{d V_{L}}{d t}=\nabla \cdot \frac{k}{\mu} \nabla p
$$

where $\mathrm{V}\left(\equiv V_{L}+V_{S}\right.$ ) is total volume with $\mathrm{V}_{\mathrm{S}}$ being the solid-phase (i.e., gel network) volume; $\mathrm{p}$ is the pore-liquid pressure; $\mu$ is the pore-liquid viscosity; and $k$ is the gel-network permeability. Equation 5 in one-dimensional (the film thickness direction) approximation reduces to 


$$
\frac{1}{V} \frac{d V}{d t} L=\frac{k}{\mu} \frac{\partial^{2} p}{\partial z^{2}}
$$

In arriving at Equation 6, the pore-liquid viscosity, $\mu$, is taken to be constant (a good appromixation since gelation is completed in the regime we consider), and the gel-network permeability, $k$, is assumed to be uniform in the thickness direction. For the lack of information, we adopt the empirical power-law correlation for permeability developed by Scherer (1994), which relates permeability to volume change:

$$
k=k_{0}\left(\frac{V}{V_{0}}\right)^{m_{k}}
$$

with $k_{0}$ being permeability at a reference point (taken as the initial state here) when the total volume is $\mathrm{V}_{0} ; m_{k}$ is the power-law exponent. Scherer (1994) reported that $m_{k}=2.46$ for a two-step, acid-base catalyzed silica gel. The two boundary conditions needed in solving Equation (6) are the zero liquid-mass flux condition at the impermeable substrate surface,

$$
\frac{\partial p}{\partial z}=0 \quad \text { at } \quad z=0
$$

and the pressure jump condition given by the Young-Laplace equation at the evaporating vapor/ liquid interface,

$$
p=p_{v}-\frac{2 \Upsilon \cos \theta_{c}}{r} \quad \text { at } \quad z=h
$$

where $z$ is the coordinate along the film-thickness direction and $h$ is the time-dependent film thickness. Here the radius of curvature is set to be the mean pore radius in the present analysis for convenience. This choice of radius of curvature yields the maximum capillary pressure that can be possibly realized when the pore walls are not coated with a very thin layer of gel. In reality it would certainly take some time for the radius of curvature to evolve from a flat liquid/vapor interface (or an infinite radius of curvature) to the pore radius. When the pore walls are coated with a 
very thin layer of gel, then the radius of curvature will further be reduced by twice of the coated film thickness. The treatment of varying radius of curvature and the effect of pore-wall coating on the capillary pressure (which is the driving force for pore shrinkage) are outside the scope of the present study and await future efforts.

Turning to the solid gel network, we assume that at each infinitesimal compression step, a linear stress-strain constitutive relation is adequate and that the bulk modulus is given by a power-law empirical correlation developed by Scherer (1994):

$$
d \sigma_{z z}=-E \frac{d V}{V}
$$

with

$$
E=E_{0}\left(\frac{V_{0}}{V}\right)^{m_{E}}
$$

where $E_{0}$ is the bulk modulus of the gel-network at a reference point (taken as the initial state here) when the total volume is $\mathrm{V}_{0} ; m_{E}$ is the power-law exponent. Scherer (1994) reported that $m_{E}$ $=3.03$ for a two-step, acid-base catalyzed silica gel and that $m_{E}$ ranges from 2.5 to 3.8 for alcogels (see also Scherer 1989) and aerogels (see also Pekala et al. 1991). It turns out that at the vicinity of gel point, such a power-law relation can also be obtained using the scaling law of the percolation theory (see, e.g., Sahimi 1994 for an excellent introduction on percolation theory and its applications) as shown in Figure 3.

Lastly when the shrinkage of the pore space stops, the gel film achieves its equilibrium everywhere within it; such a state is governed by the equation of equilibrium (cf. Biot 1941, Biot and Willis 1957, Garg and Nur 1973, Cairncross et. al. 1996):

$$
\nabla \cdot(\sigma+\zeta p I)=0
$$

where $\zeta$ is a scaling factor. Some researchers argued that $\zeta$ should be set to porosity $\phi$. Biot and Willis (1957) used a scaling factor of $\left(1-K_{n} / K_{s}\right)$ with $K_{n}$ and $K_{s}$ being the bulk moduli of the network and the solid material, respectively. Whereas Garg and Nur (1973) employed a scaling factor of $\left(1-(1-\phi) \mathrm{K}_{\mathrm{n}} / \mathrm{K}_{\mathrm{s}}\right)$. In the present study the scaling factor $\zeta$ was set to porosity $\phi$ for simplicity. The boundary condition for Equation 12 is that of vanishing normal stress at the drying surface:

$$
n \cdot(\sigma+\zeta p I)=0 \quad \text { at } \quad z=h
$$


In one-dimension the solution to Equation 13, with Equation 14 as its boundary condition, is given by

$$
\sigma_{z z}=-\zeta p \quad \text { for all } \quad z
$$

\section{Solution Procedure}

We first consider the case of constant rate of evaporation - i.e. $\dot{V}_{e}=$ constant - in which analytical solutions are possible. In the following we present and discuss solutions for liquid or pore volume, gel-film thickness, mean pore radius, pressure distribution in pore liquid, and average stress in the gel network solid phase.

i) Liquid or pore volume. The equation for pore volume can be easily obtained by integrating Equation 1 from $V_{\mathrm{L}}=V_{\mathrm{L} 0}$ at $t=0$ to $V_{\mathrm{L}}=V_{\mathrm{L}}$ at $t=t$ :

$$
\frac{V_{L}}{V_{L 0}}+\left(\frac{1}{\phi_{0}}-1\right) \ln \frac{V_{L}}{V_{L 0}}+\frac{\dot{V}_{e}}{\phi_{0} h_{0}} t-1=0
$$

where $V_{L 0}$ is the initial liquid or pore volume, $\phi_{0}$ the initial porosity, and $h_{0}$ the initial film thickness. In arriving at Equation 15, the total volume, $V$, is set to $V_{L}+V_{S}$ (i.e. $V \equiv V_{L}+V_{S}$ ) with $V_{S}$ being constant (i.e. the solid phase volume remains unchanged during pore shrinkage). Equation 15 can be readily solved using Newton's method.

ii) Gel-film thickness. With the pore volume given by Equation 15, gel-film thickness can be easily calculated:

$$
h=\frac{V}{A_{e}}=h_{0} \phi_{0}\left(\frac{V_{L}}{V_{L 0}}+\frac{1}{\phi_{0}}-1\right)
$$

Similarly with pore volume being given by Equation 15 , mean pore radius can be readily computed once a pore-shape model is prescribed.

iii) Mean pore radius. For a gel having pores with nearly constant pore-surface area (i.e., pore volume changes, but pore surface area remains nearly unchanged during shrinkage; see - e.g., Smith et. al. 1995 - for a discussion on the justification of the constant surface-area model), the mean pore radius is given by 


$$
r=r_{0} \frac{V_{L}}{V_{L 0}}
$$

where $r_{0}$ is the initial mean pore radius. In this case the mean pore radius is directly proportional to the liquid or pore volume. For a gel having cylindrical pores with uniform pore size, the mean pore radius is given by

$$
r=r_{0} \sqrt{\frac{V_{L}}{V_{L 0}}}
$$

In this case the mean pore radius is proportional to the square root of the pore volume. For a gel having pores that can be described using a cubic-cell model (a detailed discussion and mathematical description of the cubic-cell model has been provided by Scherer 1991), the mean pore radius is given by

$$
r=r_{0} \frac{V_{L}}{V_{L 0}}\left[\phi_{0}\left(\frac{V_{L}}{V_{L 0}}+\frac{1}{\phi_{0}}-1\right)\right]-\frac{-\frac{2}{3} x\left(\phi_{0}\right)}{x(\phi)} \frac{2 C_{1}-3 C_{2} x\left(\phi_{0}\right)}{2 C_{1}-3 C_{2} x(\phi)}
$$

where

$$
x(\phi)=\frac{C_{1}}{3 C_{2}}\left\{1+2 \cos \left[\frac{4 \pi}{3}+\frac{1}{3} \cos ^{-1}\left(1-\frac{27 C_{2}^{2}}{2 C_{1}^{3}}(1-\phi)\right)\right]\right\}
$$

and

$$
C_{1}=3 \pi \quad \text { and } \quad C_{2}=8 \sqrt{2}
$$

iv) Pressure distribution in the pore liquid. Pore-liquid pressure distribution can be obtained by integrating Equation 6 from $z=0$ to $z=h$ and utilizing Equations 7, 8, 9, 16, and 17, or 18 or 19 . Thus, for a gel film with uniform cylindrical pores, 
$p(z)=p_{v}+p_{c 0}\left\{\frac{\phi_{0}}{2} \frac{C a}{K_{0}} \frac{V_{L}}{V_{L 0}}\left[\phi_{0}\left(\frac{V_{L}}{V_{L 0}}+\frac{1}{\phi_{0}}-1\right)\right]^{-m_{k}}\left[1-\left(\frac{z}{h}\right)^{2}\right]-\sqrt{\frac{V_{L 0}}{V_{L}}}\right\}$

and for pores with a constant pore-surface area,

$p(z)=p_{v}+p_{c 0}\left\{\frac{\phi_{0}}{2} \frac{C a}{K_{0}} \frac{V_{L}}{V_{L 0}}\left[\phi_{0}\left(\frac{V_{L}}{V_{L 0}}+\frac{1}{\phi_{0}}-1\right)\right]^{-m_{k}}\left[1-\left(\frac{z}{h}\right)^{2}\right]-\frac{V_{L 0}}{V_{L}}\right\}$

where

$$
p_{c 0}=\frac{2 \sigma \cos \theta_{c}}{r_{0}}, \quad C a=\frac{\mu \dot{V}_{e}}{2 \sigma \cos \theta_{c}}, \quad K_{0}=\frac{k_{0}}{h_{0} r_{0}}
$$

v) Average stress in the gel network solid phase. Combining Equations 10 and 11, carrying out integration of Equation 10 from $V=V_{0}$ to $V=V$, and taking the initial state as stress free (i.e., $\sigma_{\mathrm{zz}, 0}=0$ at $V=V_{0}$ ) yields the average stress in the gel network, $\left\langle\sigma_{\mathrm{zz}}\right\rangle$ :

$$
<\sigma_{z z}>=\frac{E_{0}}{m_{E}}\left[\left(\frac{V_{0}}{V}\right)^{m_{E}}-1\right]
$$

vi) Final liquid or pore volume and mean pore radius. In the absence of the "springback" phenomena, the final microstructure of the gel film is governed by Equation 14; in other words, Equation 14 dictates when pore shrinkage stops. Averaging over the gel-film thickness gives

$$
\left\langle\sigma_{z z}\right\rangle=-\zeta\langle p\rangle
$$

Equation 26 states that when shrinkage stops, the stress in the gel network averaged over the film thickness is balanced by the average pressure (note, the average pressure is subambient or negative here) force multiplied by porosity. An equation similar to Equation 26 was intuitively stated by Smith et al. (1995) in order to predict the maximum shrinkage in their analysis of shrinkage during drying of silica gel. In contrast we derived Equation 26 strictly from first principles. The average pore-liquid pressure, $\langle p\rangle$, can be obtained readily by integrating Equation 22 or 23 from 
$z=0$ to $z=h$ and dividing the result by the film thickness, $h$. Thus, for cylindrical pores,

$$
\langle p\rangle=p_{v}+p_{c 0}\left\{\frac{\phi_{0}}{3} \frac{C a}{K_{0}} \frac{V_{L}}{V_{L 0}}\left[\phi_{0}\left(\frac{V_{L}}{V_{L 0}}+\frac{1}{\phi_{0}}-1\right)\right]^{-m_{k}}-\sqrt{\frac{V_{L 0}}{V_{L}}}\right\}
$$

and for pores with a constant pore-surface area,

$$
\langle p\rangle=p_{\nu}+p_{c 0}\left\{\frac{\phi_{0}}{3} \frac{C a}{K_{0}} \frac{V_{L}}{V_{L 0}}\left[\phi_{0}\left(\frac{V_{L}}{V_{L 0}}+\frac{1}{\phi_{0}}-1\right)\right]^{-m_{k}}-\frac{V_{L 0}}{V_{L}}\right\}
$$

Substituting Equations 25 and 27 or 28 into Equation 26 yields an equation for the final liquid or pore volume. Thus, for cylindrical pores,

$$
\begin{aligned}
& \frac{V_{L 0}^{m_{E}}}{\left[\phi_{0} V_{L f}+V_{L 0}\left(1-\phi_{0}\right)\right]^{m_{E}}}-1+\frac{\phi_{0} V_{L f}}{\phi_{0} V_{L f}+V_{L 0}\left(1-\phi_{0}\right)} \times \\
& \left\{\frac{p_{v}}{E_{0} / m_{E}}-\frac{p_{c 0}}{E_{0} / m_{E}}\left[\sqrt{\frac{V_{L 0}}{V_{L f}}}-\frac{\phi_{0}}{3} \frac{C a}{K_{0}} \frac{V_{L f}}{V_{L 0}} \phi_{0}^{-m_{E}}\left(\frac{V_{L f}}{V_{L 0}}+\frac{1}{\phi_{0}}-1\right)^{-m_{E}}\right]\right\}=0
\end{aligned}
$$

Similarly for pores with a constant pore-surface area:

$$
\begin{gathered}
\frac{V_{L 0}^{m_{E}}}{\left[\phi_{0} V_{L f}+V_{L 0}\left(1-\phi_{0}\right)\right]^{m_{E}}}-1+\frac{\phi_{0} V_{L f}}{\phi_{0} V_{L f}+V_{L 0}\left(1-\phi_{0}\right)} \times \\
\left\{\frac{p_{v}}{E_{0} / m_{E}}-\frac{p_{c 0}}{E_{0} / m_{E}}\left[\frac{V_{L 0}}{V_{L f}}-\frac{\phi_{0}}{3} \frac{C a}{K_{0}} \frac{V_{L f}}{V_{L 0}} \phi_{0}^{-m_{E}}\left(\frac{V_{L f}}{V_{L 0}}+\frac{1}{\phi_{0}}-1\right)^{-m_{E}}\right]\right\}=0
\end{gathered}
$$


In Equations 29 and 30, $V_{L f}$ denotes the final liquid or pore volume (i.e., when shrinkage stops). Equations 29 and 30 are very nonlinear, but they can be solved readily for $V_{L f}$ using Newton's method. Once $V_{L f}$ is known the final mean pore radius can be readily computed from Equations 17 , or 18 or 19 , depending on the pore-shape model employed.

When the volumetric evaporation rate, $\dot{V}_{e}$, can no longer be considered as constant (instead it depends on the time-dependent mean pore radius as described in Equations 3 and 4), analytical solutions or governing-equation simplifications (as in the case of constant evaporation rate) are not feasible. Instead numerical solution techniques are required because now the evaporation rate and the mean pore radius are closely coupled. Numerical time integration and Newton's method are needed to solve the governing equations for liquid or pore volume, mean pore radius, and stress in the gel network. Detailed discussion on the numerical solution technique and systematic treatment of gel drying with varying evaporation rate is outside the scope of the present report; instead they will be presented in a future report. Accordingly, in the following we focus on discussion of results computed for the case of constant evaporation rate. Preliminary results of varying evaporation rate are also presented and compared with that of constant rate of evaporation.

\section{RESULTS AND DISCUSSION}

Figure 4 displays a set of representative results for drying and shrinking of a gel film: liquid or pore volume, gel-film thickness, and mean pore radius, respectively, as a function of drying time. Here the volumetric evaporation rate per unit drying area, $\dot{V}_{e}$, was $1 \mu \mathrm{m} / \mathrm{sec}$; initial gel-film thickness, $h_{0}$, was $100 \mu \mathrm{m}$; and the initial mean pore radius, $r_{0}$, was $8.9 \mathrm{~nm}$. As expected, the pore volume, gel-film thickness, and the mean pore radius all drop rapidly as the gel-film dries. For the conditions chosen here, pore volume drops to $90 \%$ of its initial value within two minutes. If the gel film is compliant enough and constant rate of evaporation can be maintained, then the pore volume will continue to drop until the state of closest packing of the gel network is reached, which leaves some residual pore volume as can be seen in Figure 4a. In Figure 4c mean pore radii computed using three different pore-shape models are compared. It is informative that the cylindrical-pore model (in which the mean pore radius is proportional to the square root of pore volume) gives the upper bound for the mean pore radius, whereas the constant-pore-surface-area model (in which the mean pore radius is directly proportional to the pore volume) sets the lower bound. The cubic-cell pore model yields values of mean pore radius in between that predicted by the cylindrical model and that by the constant-pore-surface-area model. For the conditions chosen the cubic-cell pore model predicts that it takes two minutes for the mean pore radius to drop from $8.9 \mathrm{~nm}$ to $2.0 \mathrm{~nm}$, provided that the gel is sufficiently compliant.

Figure 5 shows another representative result: pressure distribution in the pore liquid along the film-thickness direction at various drying times. Process parameters are listed in the figure caption. Here, $z=0$ is the substrate surface and $z=h$ is the drying surface. As expected, pore-liquid pressure at the substrate surface is higher than that at the drying surface though the pressure drop is relatively small for the process parameters chosen.

Figure 6 shows yet another representative result: average stress in the solid gel-network as a function of drying time at various initial gel-modulus values. Other process parameters are listed in the 
figure caption. Also plotted in Figure 6 is the effective pressure force, which is defined as the negative of pore-liquid pressure weighted by the gel-film porosity. Here both the solid average stress and the liquid effective pressure force are made dimensionless by the initial gel bulk modulus divided by the power-law exponent, $m_{\mathrm{E}}$. For the conditions chosen here, the solid average stress rises slowly in the first minute, then rises rapidly for the next two minutes or so, and finally reaches a plateau because shrinkage of the solid gel network stops. As for the liquid effective pressure force, it reaches a value equal to the solid average stress in about 70 seconds if the initial bulk modulus is $0.8 \mathrm{MPa}$. At this point when liquid effective pressure force is balanced exactly by the solid average stress, shrinkage stops, which results in consequent plateau values for the solid average stress and the liquid effective pressure force. As the initial bulk modulus decreases, it takes longer for the liquid effective pressure force to catch up and balance the solid average stress. In fact, if the initial bulk modulus is below a certain value - for example, $0.1 \mathrm{MPa}$ - the liquid effective pressure force is always greater than the solid average stress, which means that the gel film will continue to shrink until the pores collapse to reach the state of closest packing of the gel network. The implication of this important result is that the degree of shrinkage can be controlled by manipulating the initial bulk modulus as well as other key process parameters.

Effects of process parameters on the final mean pore radius are presented in Figures $7 \quad$ - 10 . As expected, the final mean pore radius decreases with increasing surface tension, which serves as the driving force for shrinkage (Figure 7). In contrast the final mean pore radius increases with increasing initial gel bulk modulus, which represents resistance to deformation. The effect is more visible when the initial mean pore radius is large (Figure 8). For the process condition chosen and parameter ranges considered, the final mean pore radius essentially varies linearly with initial mean pore radius (Figure 9 ). Interestingly initial porosity also affects the final mean pore radius (Figure 10).

For special cases of appreciable shrinkage and large initial porosity, the final mean pore radius can be explicitly expressed as a function of initial mean pore radius, initial porosity, pore liquid tension, and initial bulk modulus as presented below:

a) Constant pore surface area model (mean pore radius is linearly proportional to pore volume):

$$
r_{f}=r_{0}\left[\frac{1}{m_{E}} \phi_{0}^{-m_{E}} \frac{r_{0} E_{0}}{2 \Upsilon \cos \theta_{c}}\right]^{\frac{1}{m_{E}-1}}
$$

b) Cylindrical pore model (mean pore radius is proportional to the square root of pore volume):

$$
r_{f}=r_{0}\left[\frac{1}{m_{E}} \phi_{0}^{-m_{E}} \frac{r_{0} E_{0}}{2 \Upsilon \cos \theta_{c}}\right]^{\frac{1}{2 m_{E}-1}}
$$


c) Spherical pore model (mean pore radius is proportional to the cubic root of pore volume):

$$
r_{f}=r_{0}\left[\frac{1}{m_{E}} \phi_{0}^{-m_{E}} \frac{r_{0} E_{0}}{2 \Upsilon \cos \theta_{c}}\right]^{\frac{1}{3 m_{E}-1}}
$$

In Equations 31,32 , and $33, r_{f}$ is the final mean pore radius - i.e., the mean pore radius at the final state when pore shrinkage stops. It is interesting to note that for the three different pore models, the dimensionless final mean pore radius (based on the initial mean pore radius) have the same functional dependence on the four process parameters with the exception of the power exponent.

One variable of practical interest is the time required to reach equilibrium - i.e., when pore shrinkage stops. Figure 11 shows the time required to reach equilibrium as a function of initial gel bulk modulus with other process parameters listed in the figure caption. For the process conditions chosen and gels with cylindrical pores, it takes less than a minute to reach equilibrium (i.e., for shrinkage to stop) if the initial gel bulk modulus is greater than $0.7 \mathrm{MPa}$; it takes less than two minutes if the initial gel bulk modulus is greater than $0.06 \mathrm{MPa}$. However, if the initial gel bulk modulus is less than $0.05 \mathrm{MPa}$, the time required to reach equilibrium rises rapidly. For gels with pores that can be approximated by a constant pore surface area model, the time required to reach equilibrium is generally longer when compared with that for gels having cylindrical pores.

Lastly Figure 12 shows preliminary results computed for a case of varying evaporation rate as given by Equation 3. As pointed out earlier, numerical integration and Newton's method are required in this case to solve for pore volume and other variables of interest; because of the governing equations being highly nonlinear and closely coupled, obtaining their solutions numerically is challenging. Here the vapor pressure in the bulk of the overlying vapor, $p_{v \infty}$, was set to zero (a good approximation when the solvent vapor is exhausted sufficiently fast); and the gel is taken to be sufficiently compliant so that the pore space shrinks as fast as the liquid is being removed from the drying surface. Figure 12a shows the volumetric evaporation rate per unit area as a function of drying time. As expected, the evaporation rate drops as the gel-film dries and pores shrink. Numerical instability was encountered at about 235 seconds of drying time, which prevented any further prediction computation. Figures $12 \mathrm{~b}$ and $12 \mathrm{c}$ show the pore volume and the mean pore radius, respectively, as functions of drying time. Also shown are that computed using a constant evaporation rate (i.e., the evaporation rate remains the same as the initial value during the course of drying) for the purpose of comparison. For the process conditions chosen, the differences between varying and constant evaporation rates are small. 


\section{CONCLUSIONS}

A simplified one-dimensional model was developed, which enables the predictions of pore volume, mean pore radius, pressure distribution in pore liquid, stress in the solid gel network, and the final mean pore radius in the pore-evolution regime during sol-gel film fabrication processes. Quantitative predictions computed from our simplified one-dimensional model show that the final mean pore radius is controlled by four parameters, namely pore-liquid surface tension (including contact angle effect), gel network bulk modulus, mean pore radius and porosity at the initial stress-free state. Our one-dimensional model can be employed to guide process design and optimization in sol-gel film fabrications.

Future efforts are needed in several areas in order to validate and advance the simplified onedimensional model presented in this report. First of all, experimental data aiming at validating the model is needed, and efforts for obtaining such data are currently in progress. A big challenge in validating our one-dimensional model lies in determination of process parameters, such as gel network modulus and pore structure, at the initial stress-free state. One particular model improvement can be made by incorporating pore-size distributions that more closely match reality. The present approach can also be improved by modeling phenomena in the gelation regime (i.e., the one preceding the pore-evolution regime that was treated in this report), which will enable determination of pore structure and network connectivity and, consequently, parameters at the initial stress-free state. Yet another area in which the present model can be advanced is on modeling phenomena in the pore-emptying regime (i.e. one following the pore-evolution regime), particularly "springback" of pore space as residual solvent is being removed, as may occur for certain types of gels (e.g., aerogels). Lastly as pores dimensions approach solvent-molecule size (e.g., on the order of a nanometer), it will be more appropriate to employ the concept of solvation forces (which originate from confinement of the solvent molecules in the pore space) instead of the convenient concept of capillary force as adopted in our simplified one-dimensional model.

\section{REFERENCES}

Biot, M. A. 1941 "General theory of three-dimensional consolidation", J. Applied Physics, Vol. 12, p. 155-164.

Biot, M. A. and Willis, D. G. 1957 "The elastic coefficients of the theory of consolidation", J. Applied Mechanics, Vol. 24, p. 594-601.

Brinker, C. J., and Scherer, G. W. 1990 Sol-Gel Science: the physics and chemistry of sol-gel processing Academic Press, Inc. San Diego, CA.

Brinker, C. J., Ashley, C. S., Cairncross, R. A., Chen, K. S., Hurd, A. J., Reed, S. T., Samuel, J., Schunk, P. R., Schwartz, R. A., and Scotto, C. S. 1996 "Sol-gel-derived ceramic films: fundamentals and applications", Chapter 5 in Metallurgical and Ceramic Coatings, edited by K. H. Stern, Chapman \& Hall, NY.

Cairncross, R. A., Schunk, P. R., Chen, K. S., Prakash, S. S., Samuel, J., Hurd, A. J. and Brinker, 
C. J. 1996 "Drying in deformable partially-saturated porous media: sol-gel coatings", Sandia Technical Report SAND96-2149.

Garg, S. K. and Nur, A. 1973 "Effective stress laws for fluid-saturated porous rocks", J. Geophysical Research, Vol. 78, p. 5911 - 5921.

Pekala, R. W., Hrubesh, L. W., Tillotson, T. M., Alvisco, C. T., Poco, J. F. and LeMay, J. D. 1991 in Mechanical Properties of Porous and Cellular Materials, edited by K. Sieradzki, D. J. Green, and L. J. Gibson (Mat. Res. Soc. Vol. 207, Pittsburgh, PA), p. 197-200.

Prakash, S. S., Brinker, C. J., Hurd, A. J., and Rao, S. M. 1995 "Silica aerogel films prepared at ambient pressure by using surface derivatization to induce reversible drying shrinkage", Nature, Vol. 374, p. 439-443. Also see Erratum:..., Vol. 375, p.431.

Prakash, S. S. 1995 Sol-gel thin film formation: novel experimentation, concepts and materials, M. S. Thesis, University of New Mexico.

Sahimi, M. 1994 Applications of Percolation Theory Taylor \& Francis, Bristol, PA.

Scherer, G. W. 1988 “Aging and drying of gels”, J. Non-Cryst. Solids, Vol. 100, p. 77-92.

Scherer, G. W. 1989 "Effect of shrinkage on the modulus of silica gel", J. Non-Cryst. Solids, Vol. 109, p. 183-190.

Scherer, G. W. 1990 "Theory of drying", J. Am. Ceram. Soc., Vol. 73, p. 3-14.

Scherer, G. W. 1991 "Cell models for viscous sintering", J. Am. Ceram. Soc., Vol. 74, p. 1523-1531.

Scherer, G. W. 1994 "Effect of drying on viscoelasticity and permeability of gel", Mat. Res. Soc. Symp. Proc., Vol. 346, Pittsburgh, PA, p. 209-215.

Scherer, G. W., Smith, D. M., Qiu, X. and Anderson, J. M. 1995 "Compression of aerogels", J. Non-Cryst. Solids, Vol. 186, p. 316-320.

Schunk, P. R., Hurd, A. J. and Brinker, C. J. 1997 "Free-meniscus coating flows", in The Fundamentals of Thin-film Coating: Implications and Technological Relevance, edited by S. F. Kistler and P. M. Schweizer, Chapman \& Hall, New York, NY.

Scriven, L. E. 1988 "Physics and applications of dip and spin coating", in Better Ceramics Through Chemistry III, edited by C. J. Brinker, D. E. Clark and D. R. Ulrich (Mat. Res. Soc. Symp. Proc., Vol. 121, Pittsburgh, PA), p. 717-729.

Smith, D. M., Scherer, G. W. and Anderson, J. M. 1995 "Shrinkage during drying of silica gel", J. Non-Cryst. Solids, Vol. 188, p. 191-206. 


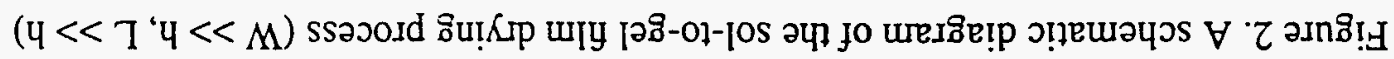

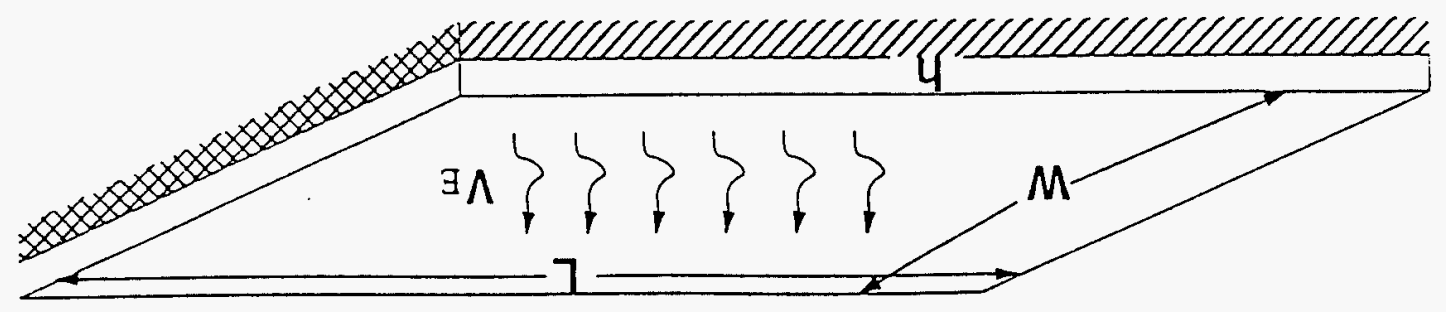

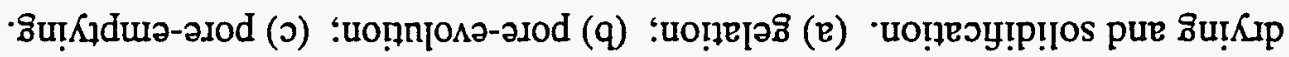

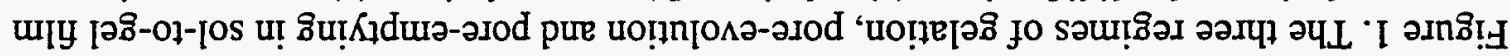

(0)

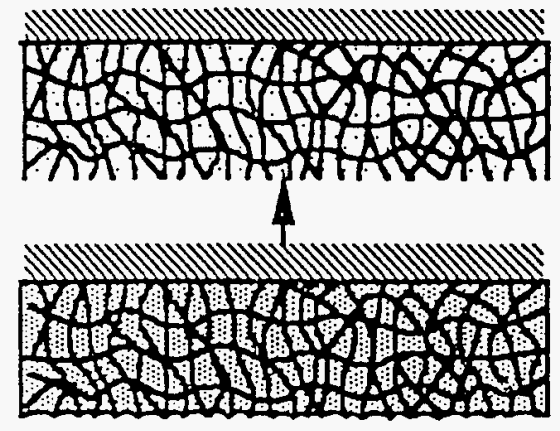

(q)

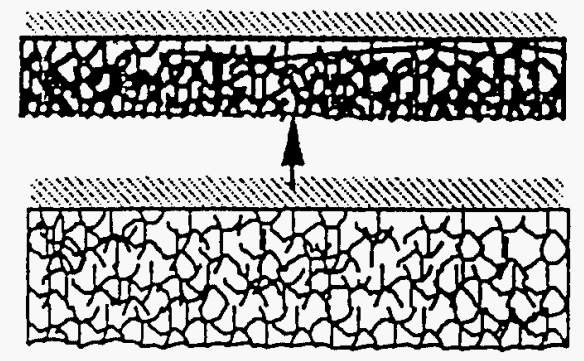

(B)

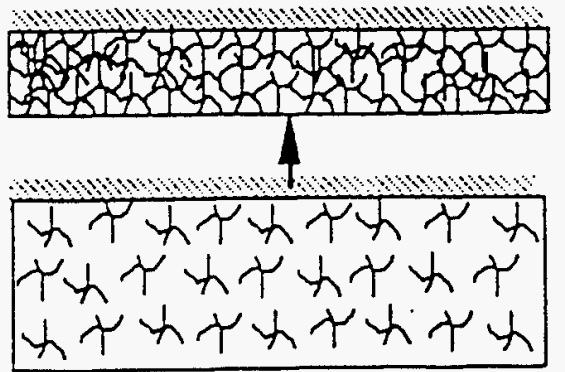




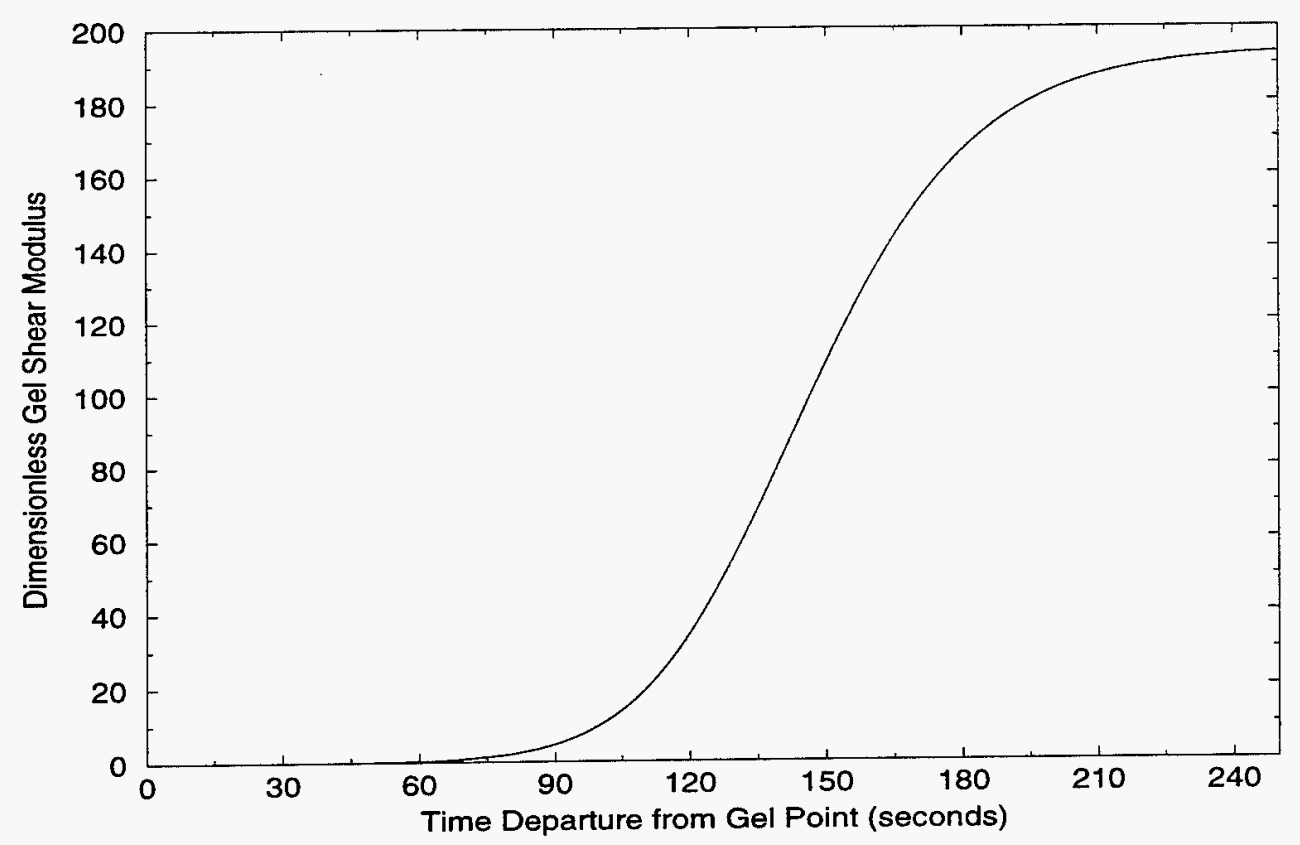

(a)

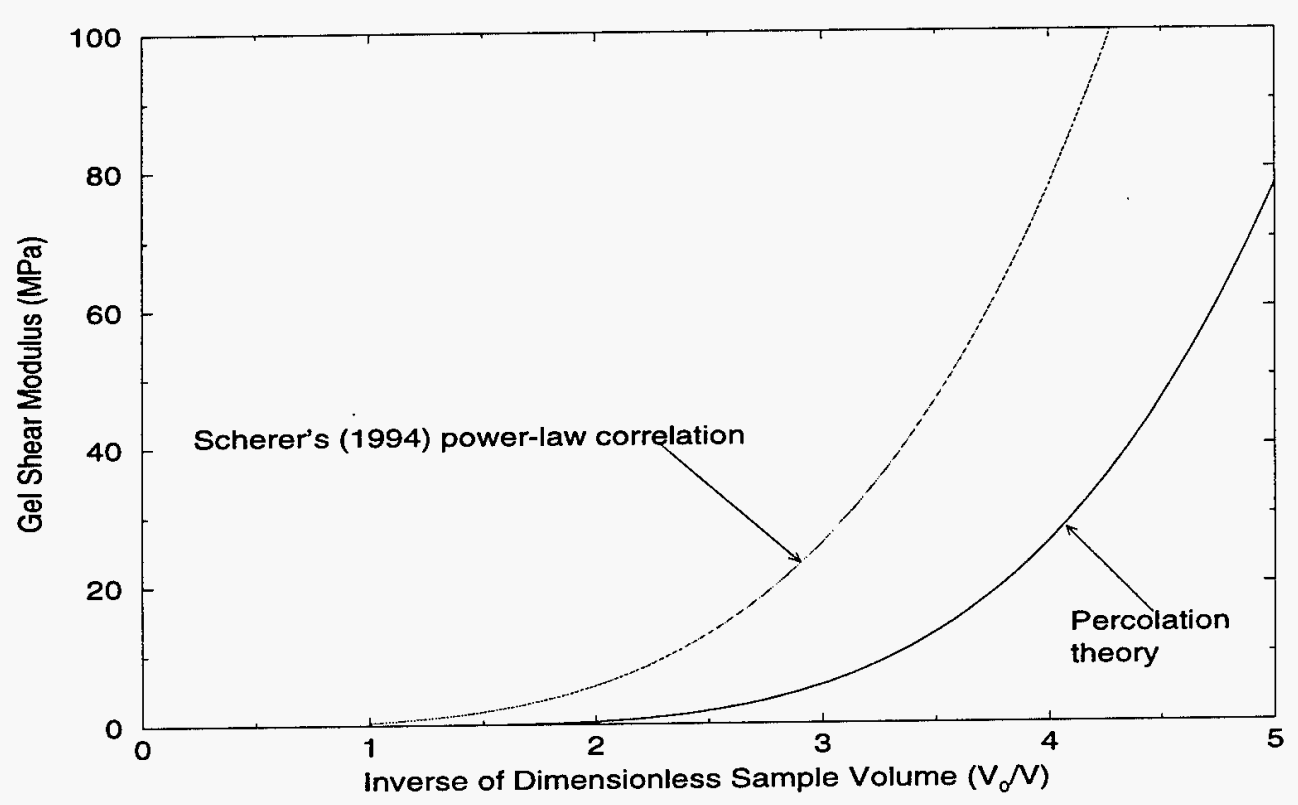

(b)

Figure 3. Gel shear modulus predicted by a scaling law derived from the percolation theory (a) shear modulus as a function of time from percolation theory, $G=\left(\frac{V_{0}}{V}-1\right)^{3.8}$ $\left(\dot{V}_{e}=1 \mu \mathrm{m}, h_{0}=100 \mu \mathrm{m}, \phi_{0}=0.8\right)$.

(b) $G$ vs. $\left(V_{0} / V\right)$ : comparison between percolation theory and Scherer's (1994) correlation, $G=G_{0}\left(\frac{V_{0}}{V}\right)^{3.8}$ with $G_{0}=0.4 \mathrm{MPa}$. 


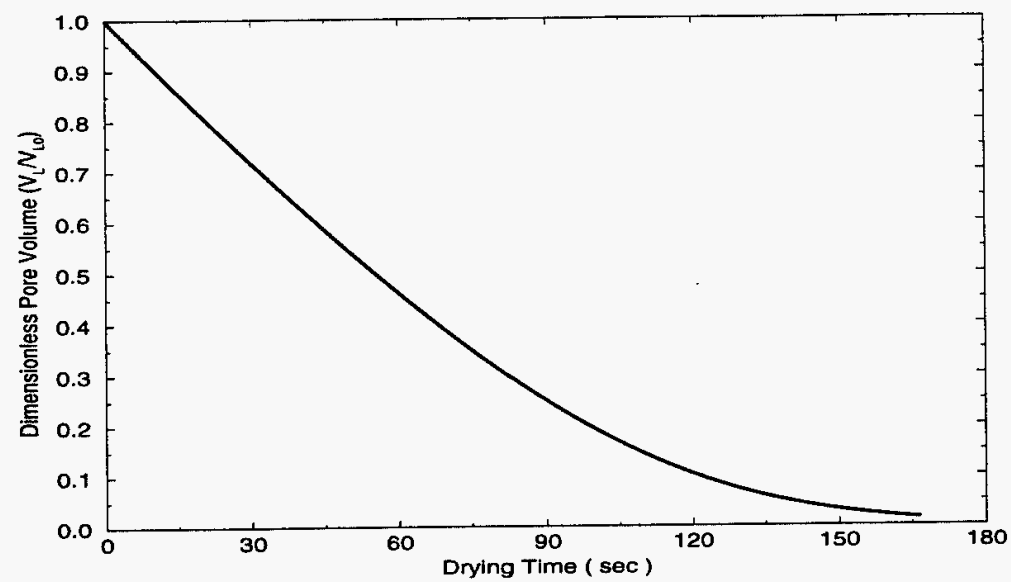

(a)

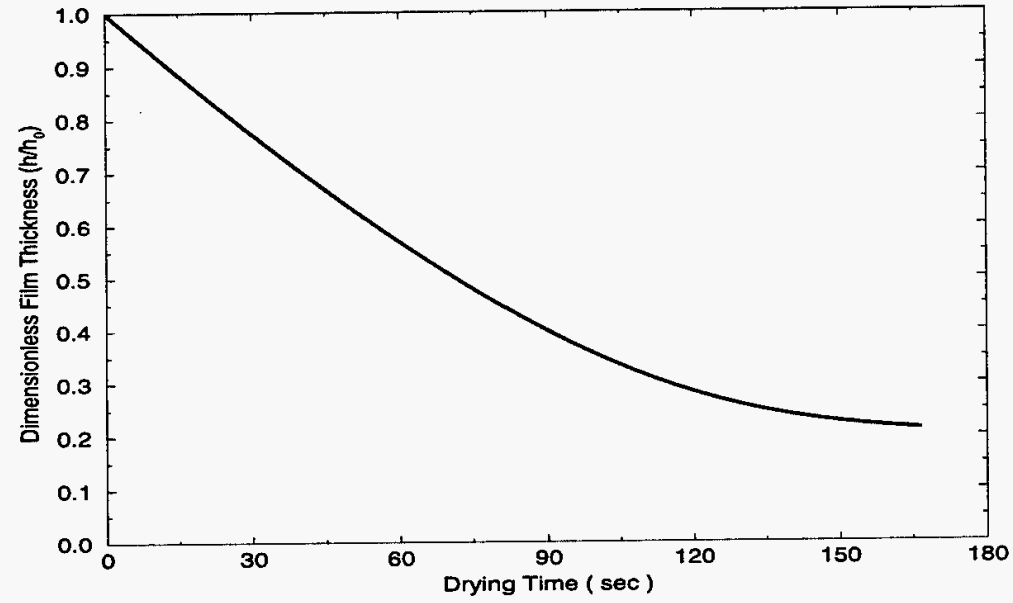

(b)

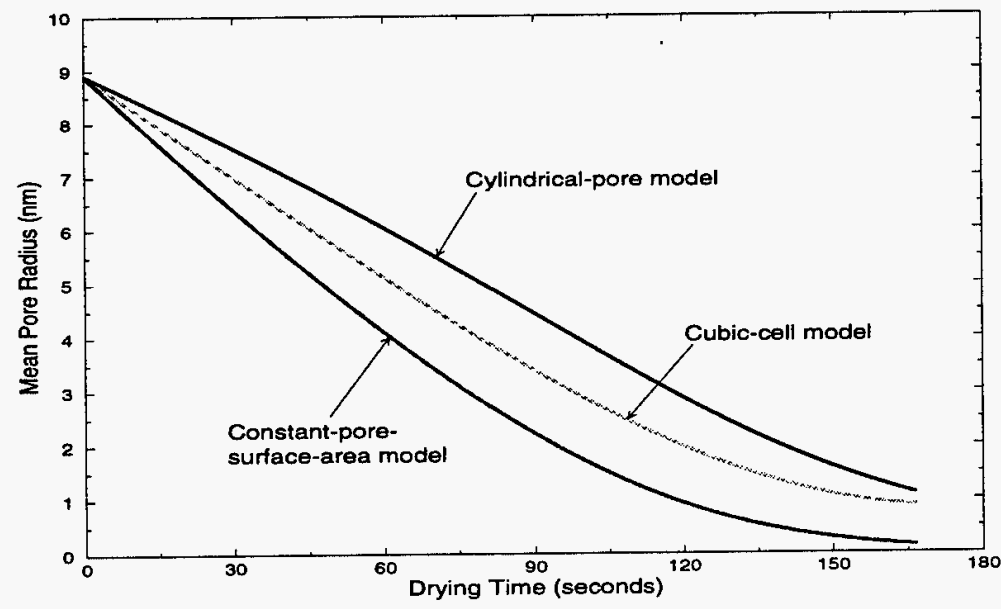

(c)

Figure 4. Representative results of gel-film drying: (a) pore volume vs. drying time, (b) film thickness vs. drying time, (c) mean pore radius vs. drying time. $\left(\dot{V}_{e}=1 \mu \mathrm{m}, h_{0}=100 \mu \mathrm{m}, \phi_{0}=0.8\right)$. 


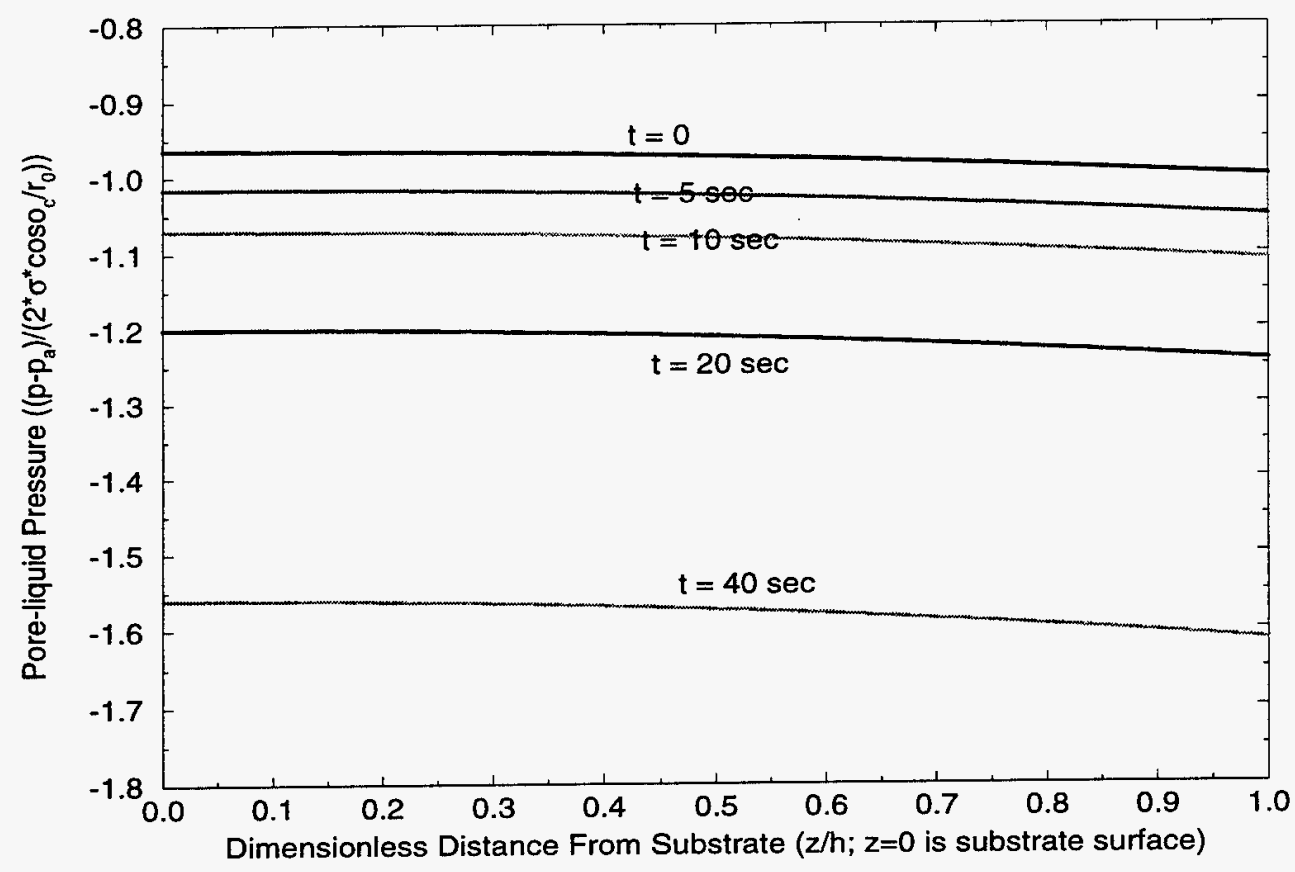

(a)

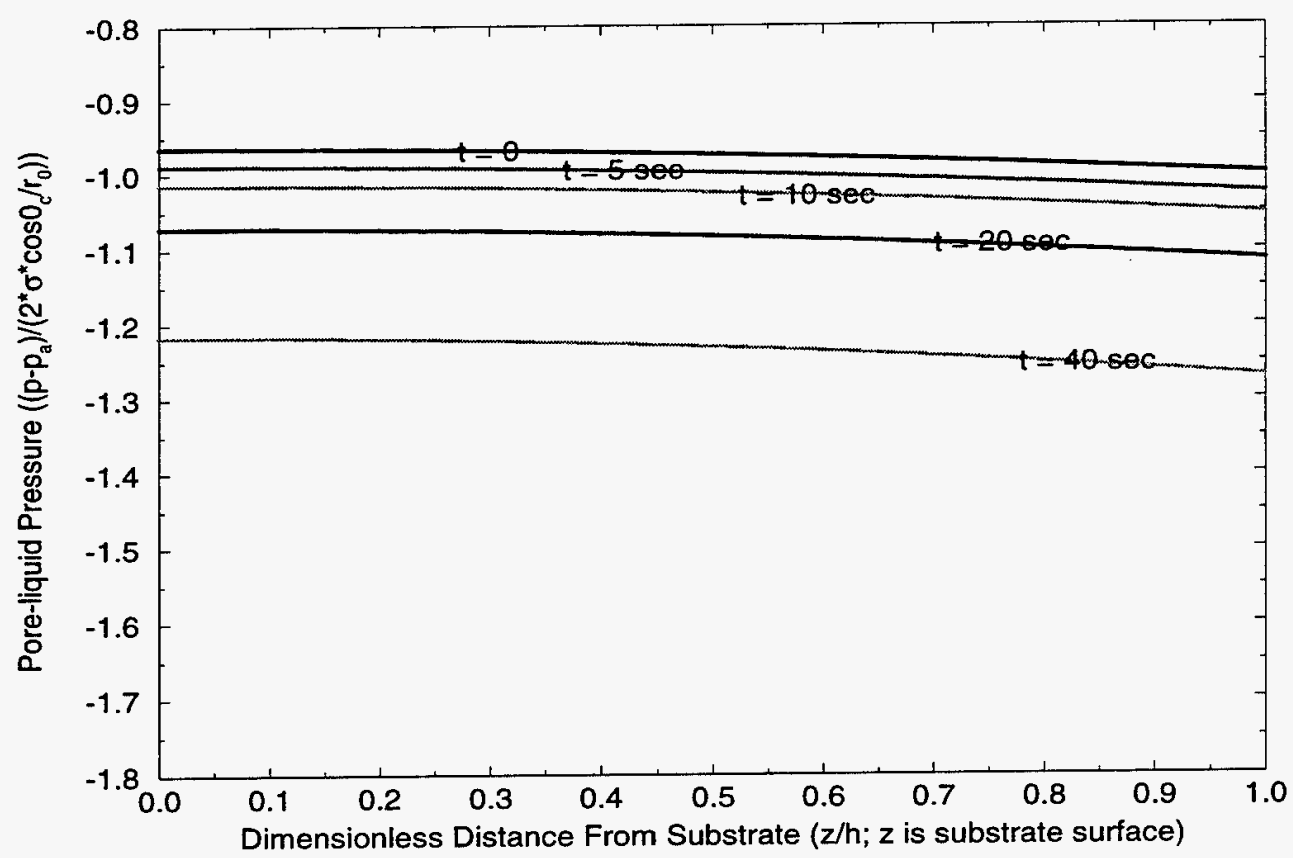

(b)

Figure 5. Representative results of gel-film drying - pressure distribution in pore liquid along film-thickness direction: a) constant pore surface area; b) cylindrical pores. $\left(m_{\mathrm{E}}=3.0, m_{\mathrm{k}}=2.46, r_{0}=8.9 \mathrm{~nm}, \phi_{0}=0.8, \gamma=5 \mathrm{dyne} / \mathrm{cm}, \mu=1 \mathrm{cP}, h_{0}=100 \mu \mathrm{m}\right.$, $\left.k_{0}=1 \mathrm{~nm}^{2}, \dot{V}_{e}=1 \mu \mathrm{m} / \mathrm{s}\right)$. 


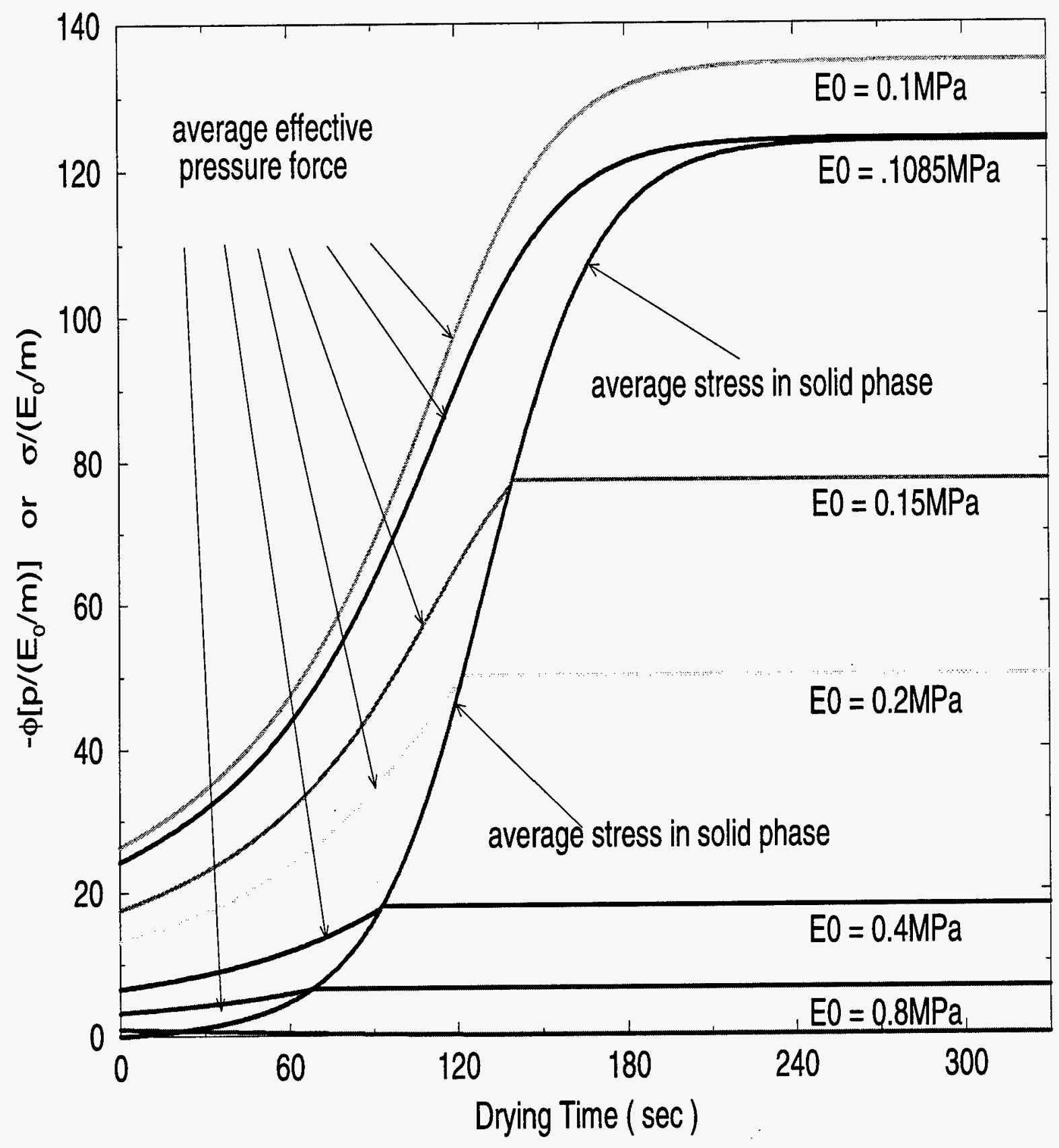

Figure 6. Representative results of gel-film drying: average stress in gel network and effective pressure force in pore liquid as functions of drying time.

$$
\begin{gathered}
\left(m_{\mathrm{E}}=3.0, m_{\mathrm{k}}=2.46, r_{0}=8.9 \mathrm{~nm}, \phi_{0}=0.8, \gamma=5 \text { dyne } / \mathrm{cm}, \mu=1 \mathrm{cP}, h_{0}=100 \mu \mathrm{m},\right. \\
\left.k_{0}=1 \mathrm{~nm}^{2}, \dot{V}_{e}=1 \mu \mathrm{m} / \mathrm{s}\right)
\end{gathered}
$$




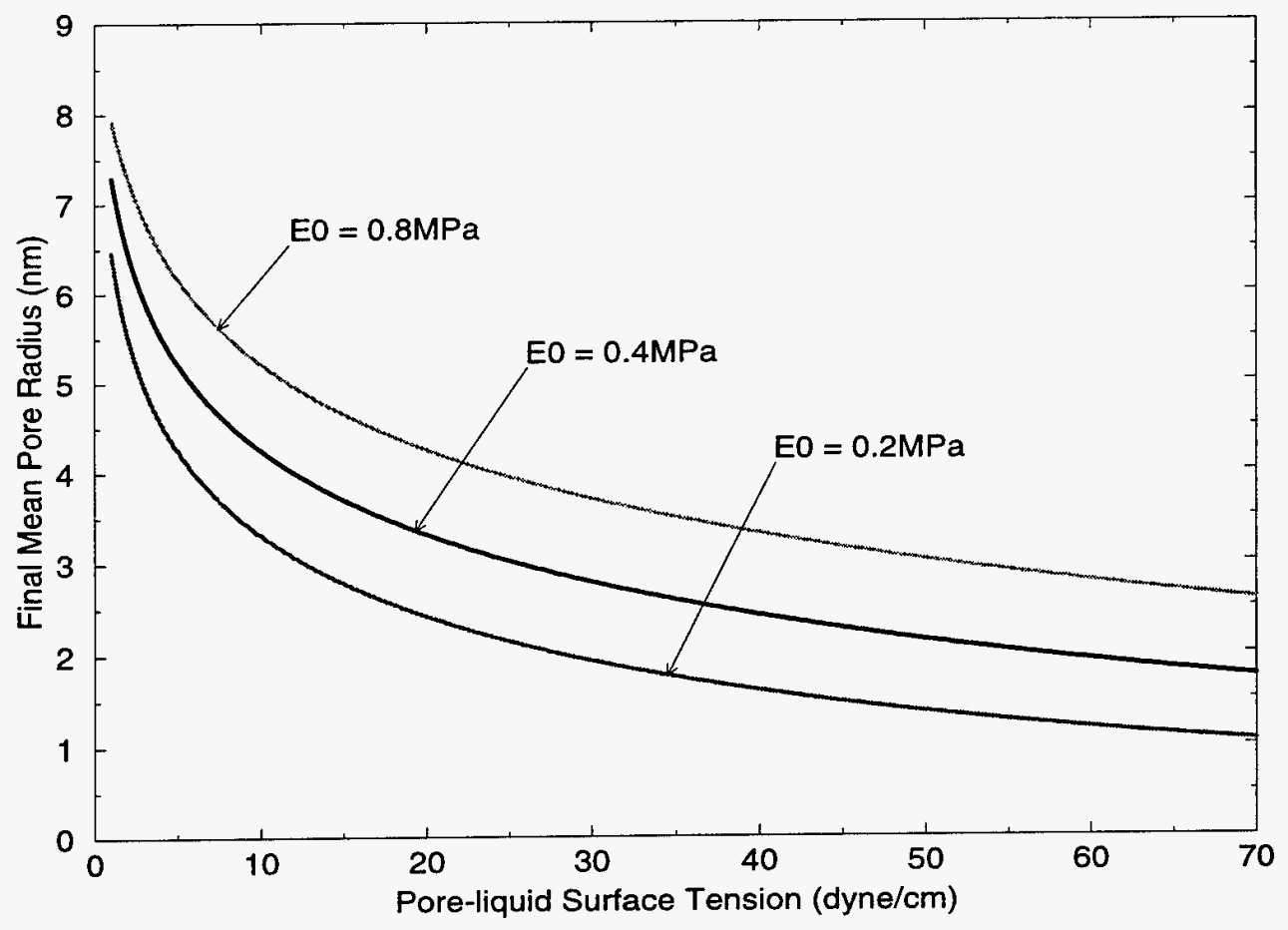

Figure 7. Effect of pore-liquid surface tension on the final mean pore radius (Cylindrical pores: $m_{\mathrm{E}}=3.0, m_{\mathrm{k}}=2.46, \phi_{0}=0.8, r_{0}=8.9 \mathrm{~nm}$ )

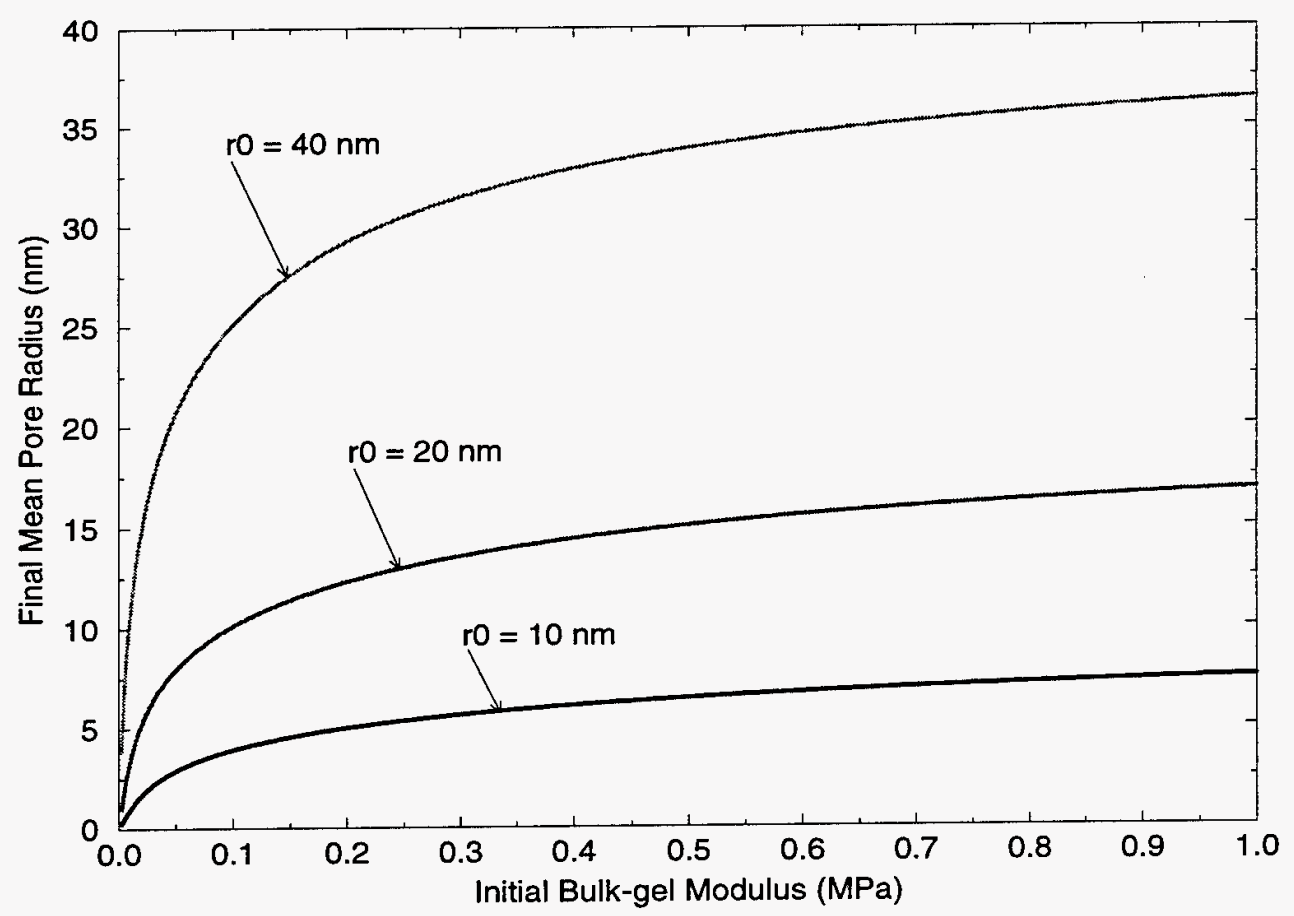

Figure 8. Effect of initial bulk modulus on the final mean pore radius

(Cylindrical pores: $m_{\mathrm{E}}=3.0, m_{\mathrm{k}}=2.46, \phi_{0}=0.8, \gamma \cos \theta_{\mathrm{c}}=5 \mathrm{dyne} / \mathrm{cm}$ ) 


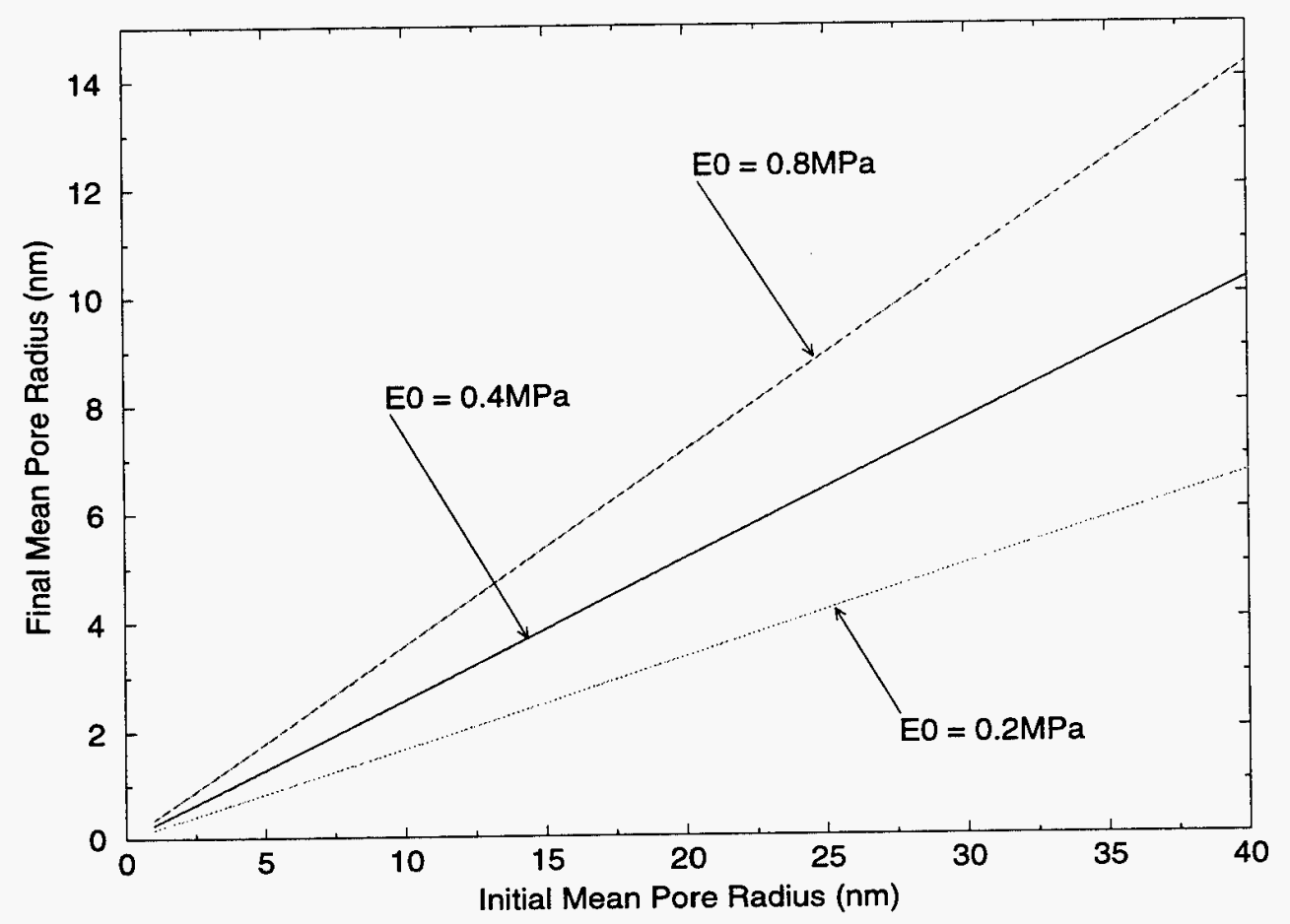

Figure 9. Effect of initial mean pore radius on the final mean pore radius (Cylindrical pores: $m_{\mathrm{E}}=3.0, m_{\mathrm{k}}=2.46, \phi_{0}=0.8, \gamma \cos \theta_{\mathrm{c}}=5 \mathrm{dyne} / \mathrm{cm}$ )

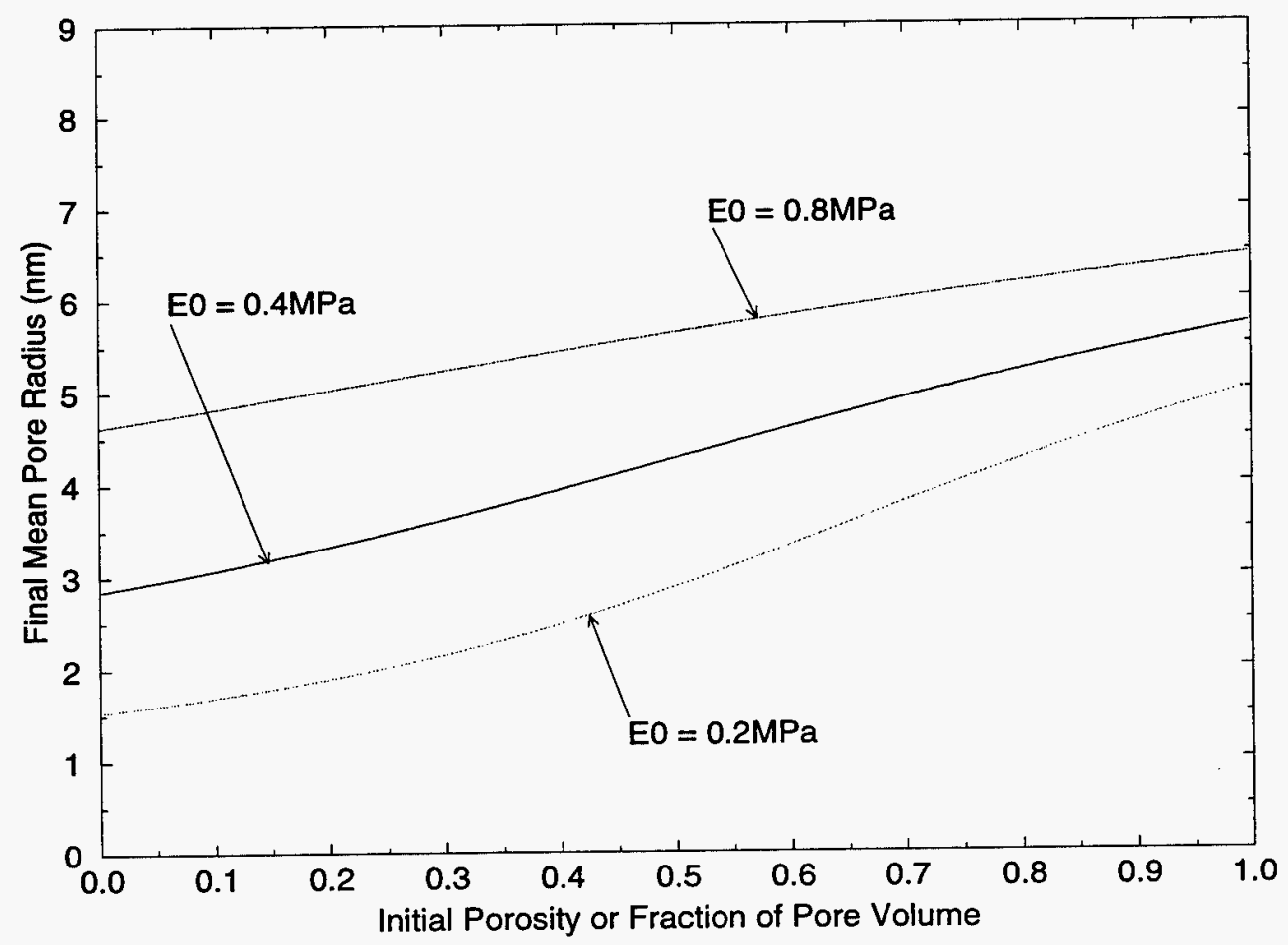

Figure 10. Effect of initial porosity on the final mean pore radius (Cylindrical pores; $m_{\mathrm{E}}=3.0, m_{\mathrm{k}}=2.46, \gamma \cos \theta_{\mathrm{c}}=5 \mathrm{dyne} / \mathrm{cm}, r_{0}=8.9 \mathrm{~nm}$ ) 


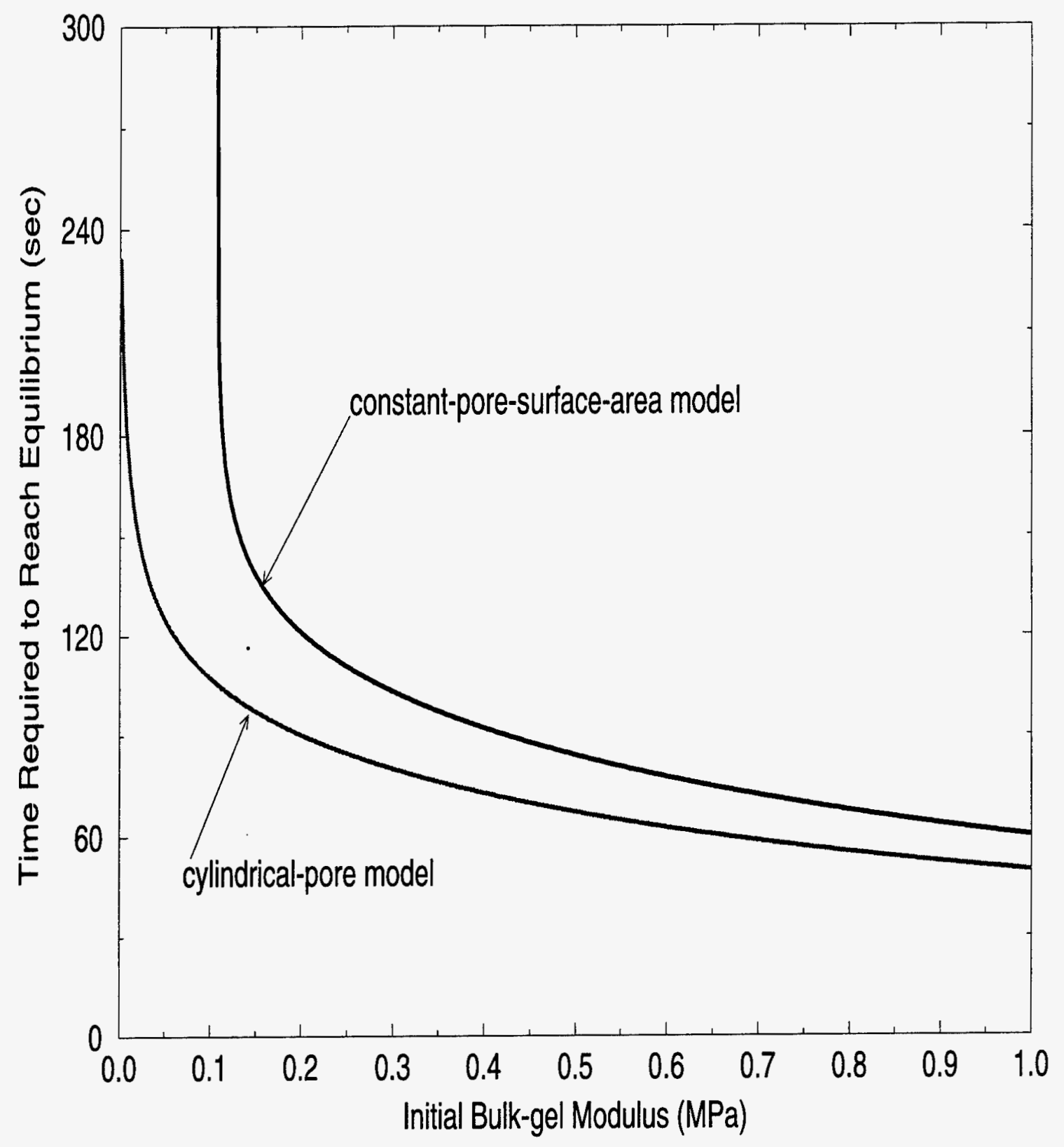

Figure 11. Time required to reach equilibrium (i.e, when shrinkage stops) as a function of initial gel bulk modulus.

$\left(m_{\mathrm{E}}=3.0, m_{\mathrm{k}}=2.46, r_{0}=8.9 \mathrm{~nm}, \phi_{0}=0.8, \gamma=5 \mathrm{dyne} / \mathrm{cm}, \mu=1 \mathrm{cP}, h_{0}=100 \mu \mathrm{m}\right.$, $\left.k_{0}=1 \mathrm{~nm}^{2}, \dot{V}_{e}=1 \mu \mathrm{m} / \mathrm{s}\right)$ 


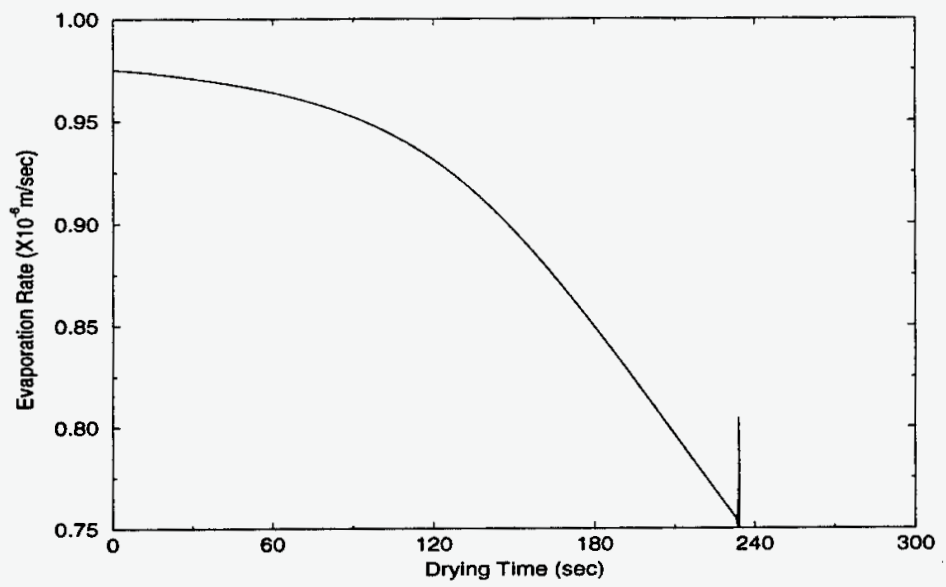

(a)

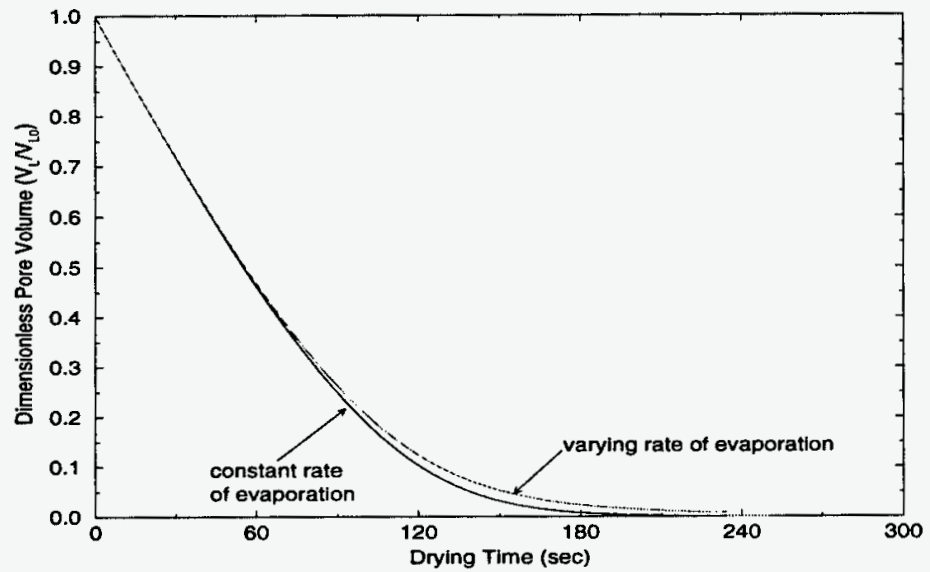

(b)

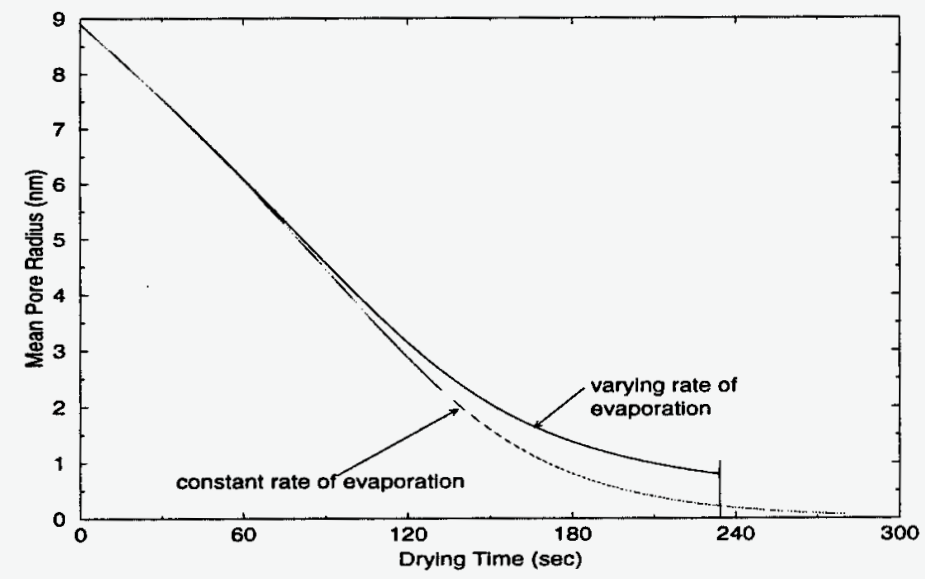

(c)

Figure 12. Effects of varying evaporation rate on the dynamics of gel-film drying:

(a) evaporation rate vs. drying time, (b) pore or liquid volume vs. drying time,

(c) mean pore radius vs. drying time (with a cylindrical-pore model).

$\left(\dot{V}_{e 0}=1 \mu \mathrm{m}, h_{0}=100 \mu \mathrm{m}, \phi_{0}=0.8, r_{0}=8.9 \mathrm{~nm}, \gamma=20\right.$ dyne $/ \mathrm{cm}$ ) 


\section{DISTRIBUTION}

Siu-yue Tam

University of New Mexico

Advanced Materials Laboratory

1001 University Blvd. S.E.

Albuquerque, NM87106

Mengcheng Lu

University of New Mexico

Advanced Materials Laboratory

1001 University Blvd. S.E.

Albuquerque, NM87106

R. A. Cairncross

Drexel University

Chemical Engineering Department

Philadelphia, PA 19104

Herong Lei

University of Minnesota

Dept. of Chem. Eng. \& mat. Sci.

421 Washington Ave. S.E.

Minneapolis, MN 55455

S. S. Prakash

University of Minnesota

Dept. of Chem. Eng. \& mat. Sci.

421 Washington Ave. S.E.

Minneapolis, MN 55455

L. E. Francis

University of Minnesota

Dept. of Chem. Eng. \& mat. Sci.

421 Washington Ave. S.E.

Minneapolis, MN 55455

L. E. Scriven

University of Minnesota

Dept. of Chem. Eng. \& mat. Sci.

421 Washington Ave. S.E.

Minneapolis, MN 55455

Josh Samuel

1/17 Ben Tabai St.

Jerusalem, Israel 93591
G. W. Scherer

Princeton University

Dept. of Civil Eng. \& Operations

Res. Eng. Quad. E-319

Princeton, NJ 08544

Zhigang Suo

Princeton University

Mech. and Aero. Eng. Dept.

Room D410, Engineering Quadrangle

Princeton, NJ 08544 
M98002892

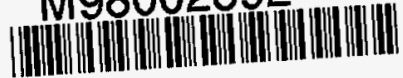

Report Number (14) SAND- $98-0451$

Publ. Date (11) 199802

Sponsor Code (18) DOE/CR,XF

UC Category (19) UC-9O5, DOE/ER

DOE 


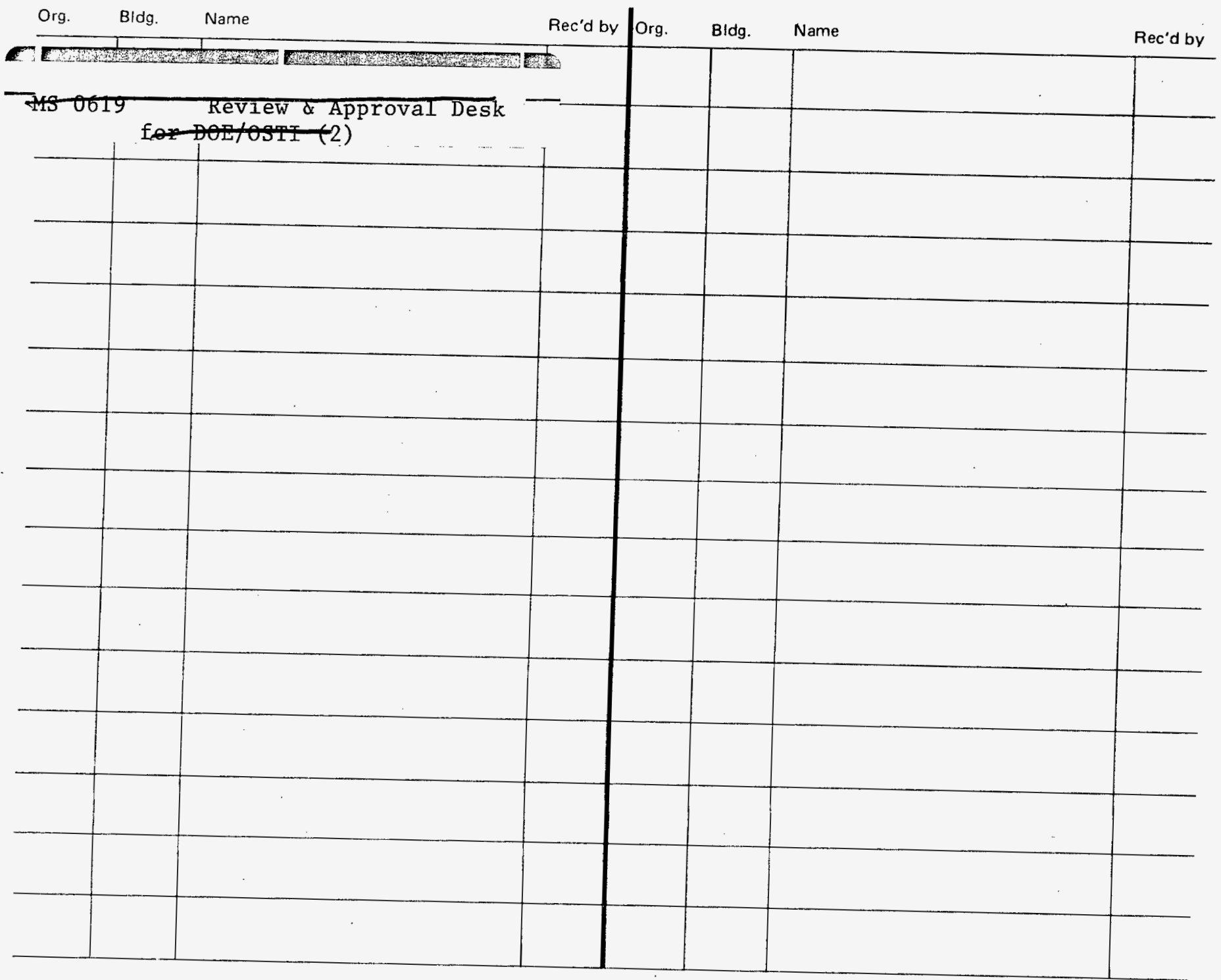

